\title{
Efficient child care subsidies: any need for cash for care?
}

\author{
Gerhard Glomm ${ }^{1} \cdot$ Volker Meier ${ }^{2}$
}

Received: 27 June 2018 / Accepted: 9 April 2020 / Published online: 19 May 2020

(c) The Author(s) 2020; This article is published with open access at Springerlink.com

\begin{abstract}
We model choices between caring for an infant at home or through some market provision of child care. Maternal labor supply necessitates child care purchased in the market. Households are distinguished along three dimensions: (i) exogenous income, (ii) the wage rate of the primary care giver and (iii) the quality which the primary caregiver provides for child care. The market can supply child care at varying qualities and in continuous amounts. All households value consumption and child care quality. Sources of market failure comprise taxation of labor and productivity impacts on child care not fully taken account of by parents. Optimal corrective subsidies are highly correlated with taxed paid by secondary earners. In a second-best environment, typical policies of subsidizing child care will also distort quality choices. Employing "no-use subsidies" mitigates such distortions and can also counter excessive levels of subsidies for external child care.
\end{abstract}

Keywords Child care $\cdot$ Labor supply $\cdot$ Subsidies $\cdot$ Family policy

JEL classifications $\mathrm{D} 13 \cdot \mathrm{H} 21 \cdot \mathrm{J} 13 \cdot \mathrm{J} 18 \cdot \mathrm{J} 22$

\section{Introduction}

The provision and financing of child care varies substantially across countries. For example, child care facilities are often publicly provided and heavily subsidized in France and Sweden, while there is no similarly strong intervention in the child care market in the UK. These radically different approaches to child care policy in the former countries all lead to rates of formal child care of around 30-45\% (in 2006) of

Gerhard Glomm

gglomm@indiana.edu

$\bowtie$ Volker Meier

meier@ifo.de

1 Department of Economics, Indiana University, Wylie Hall, Bloomington, IN 47405, USA

2 Ifo Institute for Economic Research, Poschingerstr. 5, D-81679 Munich, Germany 
children below age 3, which lies considerably above the European average (DICE Database 2011). Moreover, Finland, Sweden, Norway and Germany have experimented with cash for care, henceforth called no-use subsidies, where lump-sum payments are granted to parents with children at infant age who do not use public or subsidized private child care facilities. Thus, these subsidies are paid both if parents take care for their children or if unsubsidized external child care is chosen. The empirical literature from Heckman (1974) on argues repeatedly that increased access to subsidized child care raises labor supply of mothers (eg Lefebvre and Merrigan 2008; Herbst 2010; Bauernschuster and Schlotter 2015; Morissey 2017), while it remains unclear whether there is also a significant positive effect on fertility (Bick 2016; Bauernschuster et al. 2016). In advanced economies, as suggested by Havnes and Mogstad (2011), analyzing the expansion of kindergarten in Norway, it may happen that public child care supply simply crowds out private alternatives with little impact on maternal labor supply. Conversely, increasing parental care allowances has been found to reduce labor supply of mothers in Finland (Kosonen 2014) and Germany (Gathmann and Sass 2018).

Two main policy questions arise from these mixed observations which we address in this paper. First, which factors determine efficient subsidies for market care, and how? Second, is there any allocative justification for introducing no-use subsidies in the presence of an optimized scheme of market subsidies? And if not, which types of policies regarding market care subsidies call for complementing them by granting cash for care, and why?

We study household's child care choices where parental care and external care can be substituted on a continuous basis. While higher wages for secondary earners generally drive up the demand for external care, higher incomes of primary earners may work in the opposite direction. When replacing lower by higher quality of external care, this will often go along with an upward jump in household labor supply. For simplicity, we fix labor supply of the primary earner at full time-which makes sense in a cooperative household framework if the primary earner exhibits both higher wage rate in the market and lower productivity in parental child care. We abstract from issues of uncoordinated labor supply and home production decisions as being addressed by Meier and Rainer (2015); there it turns out that optimal taxation of wages will typically be gender-specific being determined both by Ramsey-type labor supply elasticity considerations and Pigouvian impacts of encouraging home production. Finally, we exclude rationing of access to child care subsidies, which has been employed at least temporarily in some countries due to insufficient funding of the program (Del Boca and Vuri 2007; Guzman 2019).

The main focus of our analysis lies in determining a scheme of optimal subsidies for child care. The decision between supplying labor and purchasing child care in the market on the one side and caring for the own children at home on the other side is distorted by wage taxation. As home production cannot be taxed, secondary earners with low productivities in the labor market are inclined to stay at home and care for their children themselves. We show that optimal subsidies for external care increase in the wage and the marginal tax rate of the secondary earner, and fall with a higher price of external care. This structure turns out because optimal subsidies are designed so as to perfectly offset the distortions from taxing wages of secondary earners. If subsidies for external child care are set at an excessive level, a justification of no-use 
subsidies arises. In that case we determine optimal levels. Finally, parents may have imperfect altruism towards their children or underestimate the impact of child care quality on their children's wellbeing and future productivity. Such a situation may be dealt with by reduced subsidies for market care or increasing no-use subsidies.

If there is quality differentiation in the market for external child care, optimal subsidies are determined perfectly analogously to the basic model, undoing also distortions of choosing between types of external care, where parental care does not receive a subsidy. The rate of subsidization decreases in the price of market care. It is noticeable that for many specifications efficient market subsidies exhibit only moderate informational requirements, where preference parameters and both parental and market care quality levels can be ignored. This is due to the fact that all distortions can be undone, bringing relative prices back to laissez-faire levels. Considering finally a setting in which subsidies support only one standard quality type, households will revise their decisions at the expense of both lower and higher quality alternatives. In this situation, a new justification arises for implementing no-use subsidies to reduce welfare losses from quality choice distortions in the market. Summing up, while cash for care is never needed if efficient individualized market care subsidies are used, we identify two rationales for having them: excessive market care subsidies and selective subsidization of market care qualities.

In their comprehensive survey on the literature on the economics of child care, Blau and Currie (2006) present several justifications for government intervention, stressing positive externalities not taken into account by parents and information asymmetries, resulting in poor qualities in the child care market. This message is backed by Blau and Hagy (1998), pointing to substantial substitution effects when varying the price for some type of care in combination with low propensities to pay for quality-related attributes. In line with our findings, Baker et al. (2008), considering a day care subsidization reform in Quebec, find substantial crowding out of private day care and negative impacts of child and family wellbeing. Regarding longterm outcomes, Havnes and Mogstad (2015), studying kindergarten expansion in Norway, suggest negative impacts on children from wealthy families and positive impacts on children from a disadvantaged family background. In a similar vein, Gathmann and Sass (2018), analyzing the impacts of implementing the no-use subsidy in the German state of Thuringia, find a considerable labor supply reduction and losses in cognitive outcomes of children from poorer families. Such policies may also have an impact on siblings. According to Bettinger et al. (2014) exploiting a cash for care reform in Norway, a significant positive impact on the educational outcomes of older siblings arises with mothers staying at home due to taking up that no-use subsidy.

The theoretical literature on child care subsidies is still inconclusive. Apps and Rees (2004) argue that increasing the subsidy to formal child care financed by a cut in family allowances will increase labor supply and fertility. Distortions associated with wage taxes are smaller if child care facilities are funded or subsidized through these taxes (Blomquist et al. 2010). Looking at a life-cycle model with a capital income tax rate as additional policy instrument, Domeij and Klein (2013) derive a Ramsey rule, keeping the tax wedge constant over time and advocate full tax deductibility of child care expenses. Discussing family allowances, parental leave benefits and subsidies for external child care, Fenge and Stadler (2014) obtain 
ambiguous impacts on welfare, as any change of the composition of policy measures has asymmetric distributional implications. Kemnitz and Thum (2015) analyze changes in the balance of power of spouses, inducing inefficiently low fertility. They consider child allowances, maternal care benefits and formal child care subsidies as alternative instruments to overcome the inefficiency. Other papers investigate political economy issues. If taxes on wages are comparatively high, the childless will support substantial subsidies to day care facilities due to a higher labor supply of mothers and the resulting increase in tax revenue (Bergstrom and Blomquist 1996). However, the calibration exercise of Guner et al. (2020) also points to a substantial fraction of losers from adopting a universal childcare program. Borck and Wrohlich (2011) consider households differentiated in income voting on the size of the public childcare systems in the spirit of Epple and Romano (1996a, 1996b) where rich households opt out in favor of private childcare in tailored quality.

The papers closest in spirit to ours are Apps and Rees (2018) and Bastani et al. (2017) considering fully fledged optimal tax models where external child care quality is available at different prices and government policy is to a considerable extent driven by redistributional considerations. Apps and Rees (2018) stress that individual taxation tends to be superior to joint taxation since tax avoidance by using parental care is less pronounced. Bastani et al. (2017) presuppose joint taxation and allow for a wide range of child care policies. The government has a center-based alternative at its disposal from which the households can opt out and may further use a non-linear tax schedule, tax deductions and tax credits. In their setting child care subsidies are unlikely to be used in an optimal scheme since richer households purchase more expensive higher quality alternatives. Our contribution can be seen as complementing the Mirrleesian approach, downplaying distributional considerations as far as possible so as to highlight efficiency-based aspects. Informational asymmetries are related to parental care and external care qualities. Our paper provides value added in two directions. First, keeping the analysis simpler yields transparent characterizations how efficiency-based subsidization will be differentiated across households according to observables. Second, highlighting the political debate on cash for care policies, it indicates under which circumstances such policies can be justified.

The remainder of the paper is organized as follows. Section 2 introduces the basic model with some comparative static analysis. After showing how to overcome the distortion induced by wage taxation in Section 3, Section 4 deals with justifying cash for care subsidies. Having investigated the consequences of incomplete contracts between child and parents in Section 5, Section 6 is devoted to analysing the case of a differentiated external care supply. The final Section 7 concludes and indications directions for further research.

\section{Basic model}

Consider differentiated households. Each household has exogenous net income $Y \geq 0$, comprising all sorts of capital income and typically the net wage of the primary earner who supplies labor inelastically full time. Additional income can be earned at net wage $(1-t) w$, where $t$ is the income tax rate and $\mathrm{w} \in\left[w_{\min }, w_{\max }\right]$ represents gross 
wage, which is equal to marginal productivity. Each household has a child of infant age. Child care is available in the market at price $p$ and quality $q \in[0,1]$, and can be purchased on a continuous basis. Alternatively, the household can take care of the child at own quality $\pi \in[0,1]$. Households are differentiated according to their income $Y$ their wage rate $w$ and their child care quality $\pi$. One time unit of child care needs to be provided, either by "leisure" $1-l$ in the household or through buying units in the market. With total time endowment being equal to unity and $c$ representing consumption the budget equation reads

$$
c=Y+(1-t) w l-p l .
$$

Let the preferences of the household be given by the strictly concave utility function $U(c, z)$ where $z=q l+\pi(1-l)$ is the productivity index of child care. To keep the model tractable we use a Cobb-Douglas specification

$$
U=\alpha \ln c+\beta \ln z,
$$

with $\alpha, \beta>0$.

The Lagrangean is

$$
L=\alpha \ln [Y+(1-t) w l-p l]+\beta \ln [q l+\pi(1-l)]+\lambda_{1} l+\lambda_{2}(1-l) .
$$

The first-order condition is

$$
\frac{\partial L}{\partial l}=\frac{\alpha[(1-t) w-p]}{Y+[(1-t) w-p] l}+\frac{\beta(q-\pi)}{q l+\pi(1-l)}+\lambda_{1}-\lambda_{2}=0 .
$$

Since boundary solutions may occur, we have to distinguish the following cases:

(i) If $(1-t) w>p$ and $q>\pi$, that is, external care is more productive than parental care and its price falls short of the opportunity cost of parental care, we obtain $l=1$ that is, labor supply will be full time.

(ii) If $(1-t) w<p$ and $<\pi$, the secondary earner will specialize in child care, $l=0$ maximizing both consumption and child quality under these parameters.

(iii) If either (a) $(1-t) w>p$ and $q<\pi$, or (b) $(1-t) w<p$ and $q>\pi$, any type of interior or boundary solution may occur, $0 \leq l \leq 1$

In case of an interior solution we obtain

$$
\begin{aligned}
l & =\frac{\alpha[(1-t) w-p] \pi-\beta(\pi-q) Y}{(\alpha+\beta)(\pi-q)[(1-t) w-p]} \\
& =\frac{\alpha}{(\alpha+\beta)} \frac{\pi}{(\pi-q)}-\frac{\beta}{(\alpha+\beta)} \frac{Y}{[(1-t) w-p]} .
\end{aligned}
$$

Consider now $(1-t) w>p$ and $q<\pi$, hence the opportunity cost exceeds the price of external child care in combination with technically superior parental care, which clearly constitutes a frequent case in practice.

Lemma 1: If $(1-t) w>p$ and $q<\pi$, and labor supply lies in the interior, labor supply increases with a lower income $Y$ a lower quality of parental care $\pi$, and $a$ higher quality of external care q. If in addition exogenous income $Y$ is positive, labor supply increases with a higher net wage $(1-t) w$ and a lower price of external care $P$.

Proof. This follows directly from Eq. (5).

The Lemma can be interpreted as follows. As labor supply is the mirror image of parental care, a higher income is used to increase both consumption and the child care quality index via reducing labor supply. The positive impact of the net wage is 
not immediate at the outset as substitution and income effect work into opposite directions. It turns out that they cancel out each other in the absence of the exogenous income, while the substitution effect dominates when $Y>0$ Reducing labor supply as a response to a higher price of external care is again the consequence of a dominating substitution effect with $Y>0$, where the household substitutes external care by parental care. A higher quality of external care at given price enables the household to increase both consumption and the quality index by increasing labor supply. By contrast, a higher productivity of parental care induces more parental care and a lower labor supply, associated with sacrificing some consumption.

While Lemma 1 summarizes the comparative statics properties of an interior solution, it is important to keep in mind that there are corner solutions. Various parameter value combinations provide thresholds where the corner solutions obtain. For the setting $(1-t) w>p$ and $q<\pi$ we can deduce in Lemma 2 responses of threshold child care productivities to other parameter changes:

Lemma 2: If $(1-t) w>p$ and $q<\pi$, and $Y>0$, threshold parental care productivity at the lower boundary of labor supply $\left.\pi\right|_{l=0}$ increases with a higher net wage $(1-t)$ and decreases in $Y$ Threshold parental care quality at the upper boundary of labor supply $\left.\pi\right|_{l=1}$ also increases with a higher net wage $(1-t) w$ and falls in $Y$.

Proof. See Appendix 1.

Recalling from Lemma 1 that labor supply decreases in parental care productivity $\pi$, we generally have $\left.\pi\right|_{l=0}>\left.\pi\right|_{l=1}$. With a higher net wage of the secondary earner, the necessary level of parental care productivity to fully withdraw from the labor market will increase. Conversely, a higher exogenous income induces the secondary earner to fully specialize in household production already at a lower level of parental care productivity. An analogous reasoning applies for the level $\left.\pi\right|_{l=1}$ denoting the necessary minimum level of parental care quality that induces the household to reduce labor supply below full time.

\section{Distortion through tax}

Since the income tax distorts decisions in favor of providing child care within the household, three types of deviations from efficient allocations occur. First, secondary earners may specialize in caring for the child at home, fully withdrawing from the labor market. Second, while still choosing an interior solution, households may reduce labor supply due to the tax. Finally, households may prefer an interior solution to working full time. The distortion can be undone by an appropriate subsidy on purchasing child care in the market.

As a benchmark, we solve for first-best allocations where any revenue requirement related to the household under consideration can be met by a lump-sum $\operatorname{tax} T$. Consider the case $w>p$ and $q<\pi$. Any efficient allocation solves

$$
\max _{l} U(Y-T+w l-p l, q l+\pi(1-l))
$$

which yields $U_{c}(w-p)+U_{z}(q-\pi)=0$ in case of an interior solution, $l=0$ if $U_{c}(w-p)+U_{z}(q-\pi) \leq 0$ at $l=0, l=1$ if $U_{c}(w-p)+U_{z}(q-\pi) \geq 0$ at $l=1$. 
Wage taxes with elastic labor supply are typically distortionary. However, this distortion can be completely undone through the judicious use of an appropriate child care subsidy. For simplicity, we take both the wage tax rate $t$ and the tax revenue requirement referring to the household as given, using a specification without further redistribution across households. The government budget equation related to the household is

$$
T_{i}+t w_{i} l_{i}=\sigma_{i} p l_{i}
$$

where $\sigma_{i}$ denotes the rate of subsidization for external care granted to household $i$ and $T_{i}$ is a net supplementary household specific lump-sum tax (or transfer if $T_{i}<0$ ) which is determined as residual. With $\bar{T}_{i}, \widehat{T}_{i}, T_{i}^{g}$ representing the tax paid by the primary earner, the tax revenue requirement and the gross lump-sum tax, respectively, we obtain $T_{i}=T_{i}^{g}+\bar{T}_{i}-\widehat{T}_{i}$. In the following, we will suppress the household index as long as this does not lead to confusion.

Proposition 1. If the distortion arises through taxation of wage income, a firstbest allocation can be implemented by a subsidy $\sigma p=t w$ per unit of time.

Proof. See Appendix 2.

The optimal subsidy has the striking feature that it increases with the wage rate of the secondary earner and her marginal tax rate. This contrasts with subsidization practices in many countries where subsidies are usually higher for low income households.

Moreover, the first-best subsidy rate $\sigma=t w / p$ decreases in the market price of child care. The last property is particularly interesting as a higher price will generally turn out as a consequence of a higher quality. From the optimality condition $\sigma p=t w$, the absolute amount of the subsidy per unit of time is - at given wage and marginal tax rate of the secondary earner-independent of the price $p$. As a consequence, making expenditure on market childcare fully deductible in wage taxation, and thus setting the subsidy rate constant, will not be optimal as it distorts choices in favor of more expensive high quality alternatives.

Another reason for considering the level of the optimal subsidy as derived in Proposition 1 as an upper limit benchmark is due to our simplifying assumption that the marginal cost of raising public funds is zero. Since this cost is generally positive if there is a necessity of using distortionary taxation, taking it into account clearly reduces the optimal subsidy.

\section{Distortion through the child care subsidy}

If the child care subsidy $\sigma p$ is set too high, it distorts the decision of the household against providing parental care. This distortion may be offset by a cash benefit $b$ to parents per unit of time in which subsidized child care is not purchased in the market. Such a cash for care subsidy, called a "no-use subsidy" is in place in some Scandinavian countries and has also been implemented in Germany between 2013 and 2015 after fierce political debate. In our model, the full amount of $b$ is paid when the secondary earner fully withdraws from the labor market. Otherwise, it is reduced proportionally. Proposition 2 characterizes the optimal level of the subsidy. 
The modified government budget equation related to the household now reads

$$
T_{i}+t w_{i} l_{i}=\sigma_{i} p l_{i}+b_{i}\left(1-l_{i}\right)
$$

Proposition 2. If the distortion arises through a combination of taxation of wage income and child care subsidy, a first-best allocation can be implemented by paying a no-use subsidy $b=\sigma p-t w$ per unit of time.

Proof. See Appendix 3.

Should the subsidization rate $\sigma$ for purchasing child care in the market be constant, the optimal no-use subsidy increases in the price of market care and falls both with a higher tax rate and with a higher wage of the secondary earner. These properties are generally not satisfied by real-world no-use subsidies, which are typically constant. Since the no-use subsidy is meant to correct an imperfectly set market care subsidy, it rises when the difference between market care subsidy and tax paid by the secondary earner increases, and vice versa. Accordingly, the size of the optimal no-use subsidy $b$ increases with the subsidization rate of market child care $\sigma$. Should the no-use subsidy be paid only if demand for external care is zero, its optimal level is presumably cut to some extent to reduce the incentive to move away from interior solutions with part-time work.

Though our first-best approach suggests equivalence of systems of subsidization involving higher or lower levels of subsidies, introducing very small marginal costs of raising public funds could decide matters in favor of the lowest level of expenditures, associated with setting the no-use subsidy to zero, as in Section 3.

It should be noted that implementing a first-best allocation by employing a subsidy for market child care becomes impossible if pure leisure enters utility as an additional use of time. Denote leisure by $l_{f}$ with a modified utility function $U\left(c, z, l_{f}\right)$ and total demand for market child care $l+l_{f}$, where parental care is provided in the remaining time $l_{k}=1-l-l_{f}$. In that event, child care quality is $z=q\left(1-l_{f}\right)+\pi l_{k}$ and consumption is given by $c=Y-T+(1-t) w\left(1-l_{f}-l_{k}\right)-(1-\sigma) p\left[1-l_{k}\right]+$ $b l_{k}$. Utility maximization with respect to parental care $l_{k}$ and leisure $l_{f}$ yields as firstorder conditions in case of an interior solution:

$$
\begin{gathered}
-U_{c}[(1-t) w-(1-\sigma) p-b]+U_{z}(\pi-q)=0, \\
-U_{c}(1-t) w+U_{l f}=0 .
\end{gathered}
$$

The second condition states that at the margin the direct benefit of increasing leisure just offsets losses from lower consumption due to lower wage income. While the leisure choice is also distorted by wage taxation, its relative price is independent of child care subsidies. Appendix 4 considers a quasi-linear specification of the utility function and shows that optimal child care subsidies are still given as specified in Propositions 1 and 2. This is due to the fact that demand for pure leisure will then not react to changes of child care subsidies. Noting that this property will not hold for arbitrary preferences, efficient subsidies as derived in Propositions 1 and 2 are interpreted as expressing strong correlations rather then taken literally. 


\section{Incomplete contracts}

It may be the case that parents do not take into account the productivity impact of child care on their child in full. This can be a consequence of the impossibility of writing contracts with minors. In a complete contract world, children would most likely like to buy additional quality units of child care, but cannot.

Let the social planner's preferences be given by

$$
W(c, z ; \gamma) \equiv U\left(c, \frac{1}{1-\gamma} z\right),
$$

with $0<\gamma<1$ This function expresses the "true" preference weights for the social welfare function which derive from the fundamental benefits a child receive from child care. In this formulation the discrepancy between the social welfare weights and the parental weights is increasing in $\gamma$. We can thus take $\gamma$ as a measure of market incompleteness.

Solving the social-planner's problem results in the following first-order condition on optimal labor supply:

$$
\frac{\partial W}{\partial l}=U_{c}(w-p)+\frac{1}{1-\gamma} U_{z}(q-\pi)=0 .
$$

Proposition 3. If the market failure arises through a combination of taxation of wage income and underestimation of productivity impact of child care, the optimal level of the child care subsidy is given by $\sigma p=t w-\gamma(w-p)$ Should the child subsidy be chosen at a different level, the perfectly correcting no-use subsidy is $b=\gamma$ $(w-p)+\sigma \mathrm{p}=t w$.

Proof. See Appendix 5.

Proposition 3 shows that there is again no need to employ a no-use subsidy. Notice that for any fixed measure of market incompleteness $\gamma$ the child care subsidy is declining in the "wage surplus rate" $(w-p)$. The higher is the positive wage surplus rate $(w-p)$, the higher is labor supply and thus the purchase of external day care. If the quality of external care is lower than that for own child care, any increase in the effective wage $(w-p)$ decreases child care quality, which necessitates a decrease in the optimal child care subsidy. Similarly, for any fixed positive wage surplus rate $(w-p)$ the optimal subsidy is declining in the degree of underestimation of the productivity impact of child care as measured by $\gamma$. Should underestimation be strong enough to satisfy $\gamma>t w /(w-p)$, external care is even taxed rather than subsidized. When the wage surplus rate is negative, interior solutions combine higher quality external care with lower quality parental care. In that event, the optimal subsidy from the basic model is corrected upward.

If, for whatever reason, the child care subsidy is not set at the level given in the first part of Proposition 3, a no-use subsidy can be employed as it also directly addresses demand for market child care. For example, should the optimal child care subsidy at $b=0$ be negative, the social planner's choice can be achieved also by combining $\sigma p=0$ with a no-use subsidy $b=\gamma(w-p)-t w$.

Note that none of the optimal child care subsidies derived up to now requires information about preference parameters of the households and parental care productivity. In Sections 3 and 4, only market care prices, wages and tax rates matter, 
which are in principle observable. This result turns out because undoing distortions is possible here by simply correcting relative prices. It is however no longer true in the incomplete contract scenario in the likely event that the degree of underestimation of child care quality varies across households. Following an analogous intuition, even then some additional knowledge about the individualized underestimation coefficient $\gamma$ suffices to construct the optimal subsidy scheme.

\section{Differentiation of quality}

\subsection{Setup}

Suppose now that quality of market care $q$ is continuously differentiated, associated with a unit price $p(q)$. For simplicity, demand for different types of market child care is mutually exclusive, while each quality type can be combined with parental care on a continuous basis, $z=q l+\pi(1-l)$ again describing the productivity index of child care. In order to avoid zero demand for dominated alternatives, we need to assume that the price per unit of quality $\frac{p(q)}{q}$ increases in quality, implying $p^{\prime}(q)>\frac{p(q)}{q}$. Otherwise, some lower quality is at least weakly dominated. With price per unit of quality falling in quality, the household could increase both consumption and the quality index by switching from a lower to a higher quality alternative.

For simplicity, we go back to the framework without pure leisure. The rate of subsidization may vary with the price, $\sigma(p)$ The individual then chooses labor supply and quality of market care so as to maximize $U(c, z)$ subject to $Y-T+[(1-t) w-p(q)(1-\sigma(p(q)))] l+b(1-l)-c \geq 0$.

The first-order conditions for an interior solution are

$$
\begin{gathered}
l: \frac{\partial U}{\partial c}[(1-t) w-b-p(q)(1-\sigma(p(q)))]-\frac{\partial U}{\partial z}(\pi-q)=0, \\
q:-\frac{\partial U}{\partial c}\left[p^{\prime}(q)\left(1-\sigma(p(q))-p(q) \sigma^{\prime}(p(q))\right)\right] l+\frac{\partial U}{\partial z} l=0 .
\end{gathered}
$$

Increasing market care quality at given positive labor supply yields a higher overall child care quality, which at the optimum is just offset by the utility decline via less consumption due to the higher cost of market care.

The key result on the level of optimal market care subsidies carries over to the framework with a continuum of market care qualities:

Proposition 4. If with multiple qualities the distortion arises through taxation of wage income, a first-best allocation can be implemented by a scheme of subsidies for external care, characterized by $\sigma(p(q)) p(q)=$ tw per unit of time, thus $\sigma^{\prime}(p(q))=$ $-\frac{\sigma(p(q))}{p(q)}$ with $b=0$.

Proof. See Appendix 6.

The optimal subsidy achieves a first-best allocation because it perfectly offsets wage taxation of the secondary earner. Instead of reducing wage taxation to zero, tax proceeds are returned in full to the taxpaying household such that the tax wedge vanishes. Due to this property of the subsidization scheme, it does not matter that 
labor supply can change. Labor supply will no longer be distorted, and the household's choice of external care is not associated with any fiscal externalities. There is no need to use information on parental or market care qualities because efficient subsidies restore relative prices at their laissez-faire level. All income effects are eliminated as each household finances its subsidy in full. Finally, as in the basic model, there is no justification for a no-use subsidy.

As already mentioned above, the result stands in contrast to policies aiming at deductibility of child care expenses in the income tax. Such a policy would be equivalent to fixing the subsidization rate, which in the light of Proposition 4 will distort external child care quality choices in favor of higher quality alternatives.

\subsection{Subsidizing standard care only}

An interesting issue arises from the feature of many real-world subsidies to focus exclusively on standard external care. This practice may be justified by problems of verifying child care qualities in other arrangements. Such a single-standard subsidization policy crowds out not only parental care, but also other qualities of external child care. While some poor parents will replace lower quality care arrangements by the standard quality $\tilde{q}$, some middle class households may refrain from using higher quality external care. Due to this distortion of quality choice, a new justification for implementing no-use subsidies arises that holds even if the subsidy for standard quality care is not excessive as in Section 4. Tying the no-use subsidy to the condition that standard market care is not used can then mitigate crowding out among the different sorts of external child care.

For this analysis, a Benthamite social planner is introduced, where all households have to be treated in a uniform fashion. Consider an environment in which a price subsidy $\sigma p(\tilde{q})$ per unit of time for standard care is paid. Those who do not use standard care receive a lump sum cash for care $b$. Let $T$ be a lump-sum tax used so as to balance the budget and $\beta$ the share of users of standard care. Hence, consumption of a user of standard care is $\tilde{c}=Y-T+[(1-t) w-(1-\sigma) p(\tilde{q}) \widetilde{]}$, associated with labor supply $\widetilde{l}(Y, w, \pi, t, \sigma)$, while consumption of a non-user is $c^{*}=Y-T+b+$ $[(1-t) w-p(q)] l^{*}$ with $q \neq \tilde{q}$, where labor supply is given by $l^{*}(Y, w, \pi, t, b)$.

Consider a continuum of households with Lebesgue measure 1. In the following, we suppress boundaries of integration for the sake of keeping the notation simple. The government maximizes a Benthamite welfare function subject to the government budget constraint:

Denote indirect utility subject to purchasing standard external care by $\widetilde{V}(Y, w, \pi, t, \sigma)$, and indirect utility when taking up cash for care by $\widetilde{V}(Y, w, \pi, t, b)$. The household uses standard care when $\widetilde{V}(Y, w, \pi, t, \sigma) \geq V^{*}(Y, w, \pi, t, b)$ and takes up cash for care if $\widetilde{V}(Y, w, \pi, t, \sigma)<V^{*}(Y, w, \pi, t, \beta)$. To describe switchers, we consider households being indifferent, characterized by $\widetilde{V}(Y, w, \pi, t, \sigma) \geq V^{*}(Y, w, \pi, t, b)$. It is obvious that $\frac{\partial \widetilde{V}}{\partial \sigma}>0, \frac{\partial V^{*}}{\partial b}>0$ while $\frac{\partial \widetilde{V}}{\partial b}=\frac{\partial V^{*}}{\partial \sigma}=0$. Thus, subsidizing one group will induce some households to switch into this group. 
Consider a continuum of households with Lebesgue measure 1. The social planner maximizes Benthamite welfare subject to the government budget constraint, ignoring distributional terms. The Lagrangian is

$$
\begin{aligned}
W=\iiint_{\widetilde{V} \geq V^{*}} \widetilde{V}(Y, w, \pi, t, \sigma) f(Y, w, \pi) d Y d w d \pi \\
+\iiint_{\widetilde{V} \geq V^{*}} V^{*}(Y, w, \pi, t, b) f(Y, w, \pi) d Y d w d \pi \\
+\lambda\left[\iiint_{\widetilde{V} \geq V^{*}}[Y+[t w-\sigma p(\widetilde{q})] \widetilde{l}(Y, w, \pi, t, \sigma)] f(Y, w, \pi) d Y d w d \pi\right. \\
\left.\quad+\iiint_{\widetilde{V} \geq V^{*}}\left[Y+t w l^{*}(Y, w, \pi, t, b)-b\right] f(Y, w, \pi) d Y d w d \pi\right] .
\end{aligned}
$$

The first-order conditions in case of an interior maximum are given as follows:

$$
\begin{aligned}
& \frac{\partial W}{\partial \sigma}= \iiint_{\widetilde{V} \geq V^{*}}\left[\frac{\partial \widetilde{V}(Y, w, \pi, t, \sigma)}{\partial \sigma}-\lambda p(\widetilde{q}) \widetilde{l}(Y, w, \pi, t, \sigma)\right] f(Y, w, \pi) d Y d w d \pi \\
&+\lambda \iiint_{\widetilde{V} \geq V^{*}}[t w-\sigma p(\widetilde{q})] \frac{\partial l(Y, w, \pi, t, \sigma)}{\partial \sigma} f(Y, w, \pi) d Y d w d \pi \\
&+\lambda \int_{s}\left\{[t w-\sigma p(\widetilde{q})] \widetilde{l}(Y, w, \pi, t, \sigma)-t w l^{*}(Y, w, \pi, t, b)+b\right\}=0, \\
& \frac{\partial W}{\partial b}=\iiint_{\widetilde{V} \geq V^{*}}\left[\frac{\partial V^{*}(Y, w, \pi, t, b)}{\partial b}-\lambda b\right] f(Y, w, \pi) d Y d w d \pi \\
& \quad+\lambda \iiint_{\widetilde{V} \geq V^{*}} t w \frac{\partial l^{*}(Y, w, \pi, t, b)}{\partial b} f(Y, w, \pi) d Y d w d \pi \\
& \quad-\lambda \int_{s}\left\{[t w-\sigma p(\widetilde{q})] \widetilde{l}(Y, w, \pi, t, \sigma)-t w l^{*}(Y, w, \pi, t, b)+b\right\}=0,
\end{aligned}
$$

where integrals with index $s$ refer to marginal switching types with $\widetilde{V}=V^{*}$.

The conditions can be interpreted as follows. The respective first lines show the direct impact on welfare and its associated fiscal cost at given behavior, evaluated at $\lambda$, the marginal welfare related to an additional dollar of government budget. For each first-order condition, its second line expresses the additional tax revenue due to the change in labor supply while remaining in the group of users or non-users of market care and - in case of the market care subsidy — the related additional cost. Finally, the third line is related to switching household now becoming users of the standard market care subsidy. This may increase or decrease tax payments depending on whether $l^{*}(Y, w, \pi, t, b)$ is higher or lower than $\widetilde{l}(Y, w, \pi, t, \sigma)$. Since all households in which one parent specializes in household production will not purchase standard market care, the typical outcome is $\widetilde{l}(Y, w, \pi, t, \sigma)>l^{*}(Y, w, \pi, t, b)$ on average. Moreover, switching households now receive the market care subsidy $\sigma p(\widetilde{q}) \widetilde{l}(Y, w, \pi, t, \sigma)$ and forgo the cash for care benefit $b$.

The respective first lines in the first-order conditions are related to the redistributive motive of the social planner and will therefore be ignored for our purposes.

Proposition 5 collects the findings on the structure of optimal subsidies.

Proposition 5. If the policy set is given by a uniform price subsidy of standard care $\sigma p(\widetilde{q})$ per unit of time and a lump-sum no-use subsidy $b$, and if distributional impacts are ignored: 
(i) Any optimum with a positive no-use subsidy $b>0$ is associated with a positive fiscal impact of households switching away from using standard care at the margin.

(ii) A positive no-use subsidy will be implemented if and only if with optimized price subsidy of standard care given $b=0$ the fiscal surplus due to households switching away from using standard care outweighs tax revenue losses due to reductions of labor supply.

(iii) The uniform price subsidy $\sigma p(\widetilde{q})$ will always be positive if secondary earners of marginal households on average pay higher taxes when using standard care, $t \int_{s}\left[w\left(\widetilde{l}-l^{*}\right)\right]>0$. With an interior solution for the no-use subsidy $b>0$, it will fall short of the following weighted average tax paid by secondary earners of inframarginal users of standard care: $\int\left[t w-\sigma p(\widetilde{q}) \frac{\tilde{\partial l}}{\partial \sigma}>0\right]$. If the optimal nouse subsidy is found at the lower boundary $b=0$ the optimal uniform price subsidy falls short of the following weighted average tax paid by secondary earners of inframarginal and marginal users of standard care: $\int[t w-\sigma p(\widetilde{q})] \frac{\partial \vec{l}}{\partial \sigma}+\int_{s}[t w-\sigma p(\widetilde{q})] \widetilde{l}>0$.

(iv) The no-use subsidy will be smaller than the average subsidy paid to marginal users of standard care, $\int_{s} b<\sigma p(\widetilde{q}) \int_{s} \widetilde{l}$, if marginal secondary earners pay higher taxes when being users of standard care, $t \int_{s}\left[w\left(\widetilde{l}-l^{*}\right)\right]>0$.

\section{Proof. See Appendix 6}

The message of Proposition 6 is as follows. Employing a no-use subsidy makes sense only if introducing the subsidy yields a fiscal surplus at the margin via inducing households to switch away from subsidized child care. This is however not sufficient as the income effect of the no-use subsidy reduces labor supply of recipients and hence, tax revenue. Therefore, should a no-use subsidy be implemented, we will have a positive fiscal impact of households switching away from using subsidized standard care even at the optimum. However, the presence of market care alternatives affects the optimal subsidy even if no-use subsidies remain absent. In that event, the optimal price subsidy falls short of the tax paid by an average secondary earner among users of standard care. This happens because non-using households then have an unambiguous positive impact on the government budget, which is lost when inducing these same households to become users of standard child care.

\section{Concluding discussion}

The messages from our analysis challenge several practices of child care policies. Optimal subsidies for external child care are generally positive and increase both in wages of secondary earners and their marginal tax rates. Given progressive wage taxes, this finding suggests to use the tax system so as to implement a basically nonredistributive scheme of subsidization in which double-earner households with high wages and high tax burden will receive high subsidies. When different types of child care quality are available in the market, higher prices will be associated with smaller subsidization rates. This is a consequence of the general property of the subsidization 
scheme in our benchmark scenario to fully compensate wage taxation of secondary earners through child care subsidies and thereby eliminate the distorting impact of the government. As far as the incomplete contract argument is perceived as relevant, the optimal subsidy will generally fall short of the marginal wage tax. No-use subsidies may play an important role in order to reduce distortions in quality choice if, for whatever reason, some standard versions of external child care receive preferential treatment by the government.

The model could be extended in various directions. First, it is certainly interesting to delve deeper into the framework with leisure as an alternative use of time, which always remains untaxed. This could entail (i) more general preferences besides quasilinear ones, (ii) taking future wage income losses into account allowing for a nonlinear cost of working hours reduction, and (iii) becoming more specific about the child care quality output which could include long-term impacts on future human capital of the child. If leisure replaces market work, the distortion through wage taxation loses in weight, reducing subsidies for external child care at any given amount of market child care both in relative and absolute terms. In particular, if the secondary earner does not work, the optimal subsidy for market child care is zero. Thus, subsidizing market child care is no longer a substitute for exempting secondary earners from wage taxation. Relatedly, our analyses often allow for explicit results on optimal subsidies by arbitrarily setting the marginal cost of public funds to zero. Should these marginal costs of public funds be non-zero, the levels of optimal subsidies will be lower than stated here. Second, the external care provider may be part of the extended household, say the grandmother. If her opportunity cost is given by her net wage, the choice between parental care and external care is no longer distorted by taxation. Accordingly, with a proportional wage tax, the optimal subsidy for external care is zero in our baseline scenario. With multiple qualities of external child care, the case of providing cash for care to avoid quality distortions is weakened, yielding higher subsidy for standard care combined with a smaller no-use subsidy. Third, should the government pursue also a redistributive goal, policy changes are presumably ambiguous. While single-earner households tend to have lower incomes than double earners, the opposite may hold when comparing resulting utility levels. An interesting and plausible scenario arises with positive correlation between parental care productivity and wages. In that event, using regressive subsidies as described here instead of uniform transfers could backfire in terms of children's development: children from wealthier backgrounds may lose as some higher quality parental care is replaced by market care; conversely, disadvantaged children may lose access to superior market care, in line with the findings of Baker et al. (2008) and Gathmann and Sass (2018). Finally, it is uncertain as to how prices of external care are distorted upward by wage taxation. Standard tax incidence arguments suggest that when less elastic labor supply in the external child care market meets considerable more elastic labor demand, the lion's share of the burden of wage taxation will fall on the labor supply side, implying little impact on prices. Hence, changes to the subsidies derived here may remain small.

Acknowledgements We would like to thank Ray Rees, Bernhard Schmidpeter, Hans-Werner-Sinn, Matthias Wrede, Shoshana Grossboard (Editor), Chiara Monfardini (Co-Editor), and two anonymous reviewers for helpful comments on an earlier version of this paper, which circulated under the title "Modes of child care". Open Access funding provided by Projekt DEAL. 


\section{Compliance with ethical standards}

Conflict of interest The authors declare that they have no conflict of interest.

Publisher's note Springer Nature remains neutral with regard to jurisdictional claims in published maps and institutional affiliations.

Open Access This article is licensed under a Creative Commons Attribution 4.0 International License, which permits use, sharing, adaptation, distribution and reproduction in any medium or format, as long as you give appropriate credit to the original author(s) and the source, provide a link to the Creative Commons license, and indicate if changes were made. The images or other third party material in this article are included in the article's Creative Commons license, unless indicated otherwise in a credit line to the material. If material is not included in the article's Creative Commons license and your intended use is not permitted by statutory regulation or exceeds the permitted use, you will need to obtain permission directly from the copyright holder. To view a copy of this license, visit http://creativecommons.org/licenses/by/4.0/.

\section{Appendix}

1. Proof of Lemma 2. The boundaries can be determined by setting $l=0$ and $l=$ 1 in Eq. (5). At the lower boundary with specialization in home production solving for $\pi$ gives

$$
\left.\pi\right|_{l=0}=\frac{\beta q Y}{\beta Y-\alpha[(1-t) w-p]}=\frac{q}{1-\frac{\alpha}{\beta} \frac{[(1-t) w-p]}{Y}},
$$

which increases in $w$ and decreases in $Y$.At the upper boundary, solving for $\pi$ yields

$$
\begin{aligned}
\left.\pi\right|_{l=1} & =\frac{q[\beta Y+(\alpha+\beta)[(1-t) w-p]]}{\beta[Y+(1-t) w-p]} \\
& =q+\frac{\alpha}{\beta} q \frac{1}{1+\frac{Y}{(1-t) w-p}},
\end{aligned},
$$

which again increases in $w$ and falls in $Y$.

2. Proof of Proposition 1. Using a subsidy $\sigma p=t w$, the household maximizes

$$
\max _{l} U(Y-T+(1-t) w l-(1-\sigma) p l, q l+\pi(1-l),
$$

which yields in case of an interior solution

$$
U_{c}((1-t) w-(1-\sigma) p)+U_{z}(q-\pi)=0,
$$

thus

$$
\frac{U_{c}}{U_{z}}=\frac{\pi-q}{(1-t) w-(1-\sigma) p} .
$$

This coincides with the efficient solution iff

$$
\frac{U_{c}}{U_{z}}=\frac{\pi-q}{w-p},
$$

which requires $\sigma p=t w$. 
3. Proof of Proposition 2. With this specification, the household maximizes

$$
\max _{l} U(Y-T+[(1-t) w-b-(1-\sigma) p] l, q l+\pi(1-l)),
$$

which yields as first-order condition in case of an interior solution

$$
U_{c}((1-t) w-b-(1-\sigma) p)+U_{z}(q-\pi)=0,
$$

thus

$$
\frac{U_{c}}{U_{z}}=\frac{\pi-q}{(1-t) w-b-(1-\sigma) p} .
$$

This coincides with the efficient solution iff

$$
\frac{U_{c}}{U_{z}}=\frac{\pi-q}{w-p},
$$

which requires $b=\sigma p-t w$.

4. Model with leisure. Consider a version with pure leisure $l_{f}$. Let $l$ be time spent working by the secondary earner and $l_{k}$ parental time spent with the child. The wage tax rate which is denoted by $t$ while a lump-sum $\operatorname{tax} T$ is used so as to balance the budget. Market care, subsidized at rate $\sigma$ is needed for attending the child both when working and when enjoying pure leisure. Cash for care $b$ is paid per unit of time not using subsidized market care. Utility is here quasi-linear, more specifically linear in consumption.The household's max problem is to choose $c, l_{f}, k$ in order to

$$
\max \alpha c+\beta \ln z+\gamma \ln l_{f},
$$

$$
\begin{gathered}
\text { s.t. } \quad c+(1-\sigma) p\left(1-l_{k}\right)=Y-T+(1-t) w\left(1-l_{f}-l_{k}\right)+b l_{k}, \\
z=\left(1-l_{k}\right) q+l_{k} \pi, \\
l+l_{f}+l_{k}=1 .
\end{gathered}
$$

We concentrate on interior solutions, where the typical setting is that parents are the more productive caregivers, $\pi>q$, while at the same time material consumption can be increased by extending labor supply, $(1-t) w-b-(1-$ $\sigma) p>0$. The first-order conditions for an interior solution are

$$
\begin{gathered}
c: \alpha=\lambda, \\
l_{f}: \frac{\gamma}{l_{f}}=\lambda(1-t) w, \\
l_{k}: \frac{\beta}{z}(\pi-q)=\lambda[(1-t) w-b-(1-\sigma) p] .
\end{gathered}
$$


Hence we obtain

$$
\begin{gathered}
l_{f}=\frac{\gamma}{\alpha} \frac{1}{(1-t) w}, \\
z=\frac{\beta}{\alpha}(\pi-q) \frac{1}{(1-t) w-b-(1-\sigma) p} .
\end{gathered}
$$

From the latter and the definition of $z$

$$
l_{k}=\frac{\beta}{\alpha} \frac{1}{(1-t) w-b-(1-\sigma) p}-\frac{q}{\pi-q} .
$$

Inserting into the budget equation yields

$$
c=Y-T+(1-t) w-(1-\sigma) p-l_{k}[(1-t) w-b-(1-\sigma) p]-l_{f}(1-t) w .
$$

Thus

$$
\begin{aligned}
c & =Y-T+(1-t) w-(1-\sigma) p-\frac{\beta+\gamma}{\alpha}+\frac{q}{\pi-q}[(1-t) w-b-(1-\sigma) p] . \\
& =Y-T+\frac{\pi}{\pi-q}[(1-t) w-(1-\sigma) p]-\frac{\beta+\gamma}{\alpha}-\frac{q b}{\pi-q}
\end{aligned} .
$$

Note that $\frac{\partial c}{\partial T}=-1, \frac{\partial c}{\partial b}=-\frac{q}{\pi-q}$ and $\frac{\partial c}{\partial \sigma}=p \frac{\pi}{\pi-q}$. In this framework, leisure time is not affected by changing child care subsidies. However, more cash for care or less market care subsidies will induce a reduction of labor supply accompanied by less consumption, while parental care time and child care quality increase,As expected, parental child care $l_{k}$ increases with higher parental care quality $\pi$, lower market care quality $q$ higher exogenous income $Y-T$ higher cash for care benefit $b$, lower work income $(1-t) w$ and higher net price of market care $(1-\sigma p)$.Due to the quasi-linear utility, leisure is exclusively determined by the net wage and does not react to child care subsidies. Optimal subsidies. The social planner maximizes welfare of a representative household: Available instruments are the market care subsidy and the cash for care parameter Let indirect utility be given by $V\left(c^{*}, z\left(l_{k}^{*}\right), l_{f}^{*}\right)=\alpha c^{*}+\beta \ln \left[z\left(l_{k}^{*}\right)\right]+\gamma \ln l_{f}^{*}$, where optimized values depend on tax parameters. The budget restriction of the government is given by $T+t w\left[1-l_{k}^{*}-l_{f}^{*}\right]-b l_{k}^{*}-\sigma p\left[1-l_{k}^{*}\right]=0$. The government takes $t$ for granted, optimizing with respect to the market care subsidy $\sigma$ and the cash for care parameter $b$, where the lump-sum tax is adapted so as to balance the budget. Denote the multiplier associated with the government budget constraint by $\lambda_{g}$, the first-order conditions are

$$
\begin{gathered}
\alpha \frac{\partial c^{*}}{\partial \sigma}+\frac{\beta}{z^{*}} \frac{\partial z^{*}}{\partial l_{k}^{*}} \frac{\partial l_{k}^{*}}{\partial \sigma}+\frac{\gamma}{l_{f}^{*}} \frac{\partial l_{f}^{*}}{\partial \sigma}-\lambda_{g}\left[p\left[1-l_{k}^{*}\right]+t w \frac{\partial l_{f}^{*}}{\partial \sigma}+[t w+b-\sigma p] \frac{\partial l_{k}^{*}}{\partial \sigma}\right]=0 \\
\alpha \frac{\partial c^{*}}{\partial b}+\frac{\beta}{z^{*}} \frac{\partial z^{*}}{\partial l_{k}^{*}} \frac{\partial l_{k}^{*}}{\partial b}+\frac{\gamma}{l_{f}^{*}} \frac{\partial l_{f}^{*}}{\partial b}-\lambda_{g}\left[l_{k}^{*}+t w \frac{\partial l_{f}^{*}}{\partial b}+[t w+b-\sigma p] \frac{\partial l_{k}^{*}}{\partial b}\right]=0 \\
\alpha \frac{\partial c^{*}}{\partial T}+\frac{\beta}{z^{*}} \frac{\partial z^{*}}{\partial l_{k}^{*}} \frac{\partial l_{k}^{*}}{\partial T}+\frac{\gamma}{l_{f}^{*}} \frac{\partial l_{f}^{*}}{\partial T}+\lambda_{g}\left[1-t w \frac{\partial l_{f}^{*}}{\partial T}-[t w+b-\sigma p] \frac{\partial l_{k}^{*}}{\partial T}\right]=0
\end{gathered}
$$

With quasi-linear utility, we have $\frac{\partial l_{f}^{*}}{\partial \sigma}=\frac{\partial l_{f}^{*}}{\partial T}=\frac{\partial l_{f}^{*}}{\partial b}=\frac{\partial l_{k}^{*}}{\partial T}=0$. Hence, $\lambda_{g}=\alpha$ from the 
third condition. Inserting into the first and second condition gives

$$
\begin{gathered}
\alpha p \frac{\pi}{\pi-q}-\beta \frac{p}{(1-t) w-b-(1-\sigma) p}-\alpha\left[\frac{p \pi}{\pi-q}-\frac{\beta}{\alpha} \frac{p}{(1-t) w-b-(1-\sigma) p}\right] \\
-\alpha[t w+b-\sigma p] \frac{\partial l_{k}^{*}}{\partial \sigma}=0, \\
-\alpha \frac{q}{\pi-q}+\frac{\beta}{(1-t) w-b-(1-\sigma) p}-\alpha\left[\frac{\beta}{\alpha} \frac{1}{(1-t) w-b-(1-\sigma) p}-\frac{q}{\pi-q}\right]=0 \\
-\alpha[t w+b-\sigma p] \frac{\partial l_{k}^{*}}{\partial \sigma}=0 .
\end{gathered}
$$

Since $\frac{\partial l_{k}^{*}}{\partial \sigma}<0<\frac{\partial l_{k}^{*}}{\partial b}$, both conditions are satisfied if and only if $t w+b-\sigma p=0$. Thus, (second-best) efficiency is achieved if $t w=\sigma p$ in combination with $b=0$ or $b=\sigma p$ $-t w$ with arbitrary $\sigma$

5. Proof of Proposition 3. From Eqs. (12) and (25), optimal corrective subsidies satisfy

$$
(1-\gamma)(w-p)=(1-t) w-b-(1-\sigma) p,
$$

which is equivalent to

$$
\gamma(w-p)=t w+b-\sigma p .
$$

With $b=0$, solving for the child care subsidy yields

$$
\sigma p=t w-\gamma(w-p) .
$$

Otherwise, the related no-use subsidy to any given child care subsidy $\sigma p$ to satisfy Eq. (42) is

$$
b=\gamma(w-p)+\sigma p-t w
$$

6. Proof of Proposition 4. The first-best allocation is derived from optimizing while ignoring distortionary taxes, thus

$$
\begin{gathered}
l: \frac{\partial U}{\partial c}[w-p(q) q]-\frac{\partial U}{\partial z}(\pi-q)=0, \\
q:-\frac{\partial U}{\partial c} p^{\prime}(q) l+\frac{\partial U}{\partial z} l=0 .
\end{gathered}
$$

Comparing these conditions to the optimality conditions at the household level (13) and (24), the first-best is decentralized by setting $b=0$ and $\sigma(p(q)) p(q)=t w$ implying $\left[p(q) \sigma^{\prime}(p(q))+\sigma(p(q))\right] p^{\prime}(q)=0$, which requires $\sigma^{\prime}(p(q))=-\frac{\sigma(p(q))}{p(q)}$. In that event, both first-order conditions are satisfied.

\section{Proof of Proposition 5.}

(i) If distributional impacts are ignored, the term $\iiint_{\widetilde{V}_{<}<V^{*}}\left[\frac{\partial V^{*}(Y, w, \pi, t, b)}{\partial b}-\lambda b\right] f(Y, w, \pi) d Y d w d \pi$ in Eq. (17) is arbitrarily set to zero. Since the number of users of cash for care increases in $b$ and $\frac{\partial l^{*}}{\partial b}<0$ by 
analogy to Lemma 1, Eq. (17) can hold with equality only if

$$
\int_{s}\left\{[t w-\sigma p(\widetilde{q})] \widetilde{l}(Y, w, \pi, t, \sigma)-t w l^{*}(Y, w, \pi, t, b)+b\right\}<0 .
$$

(ii) The no-use subsidy will be positive if and only if $\frac{\partial W}{\partial b}>0$ at optimized price subsidy $\sigma p(\widetilde{q})$ given $b=0$. This in turn requires

$$
\begin{aligned}
& \iiint_{\widetilde{V}<V^{*}} t w \frac{\partial l^{*}(Y, w, \pi, t, b)}{\partial b} f(Y, w, \pi) d Y d w d \pi \\
& \quad-\int_{s}\left\{[t w-\sigma p(\widetilde{q})] \widetilde{l}(Y, w, \pi, t, \sigma)-t w l^{*}(Y, w, \pi, t, b)+b\right\}>0
\end{aligned}
$$

at optimized price subsidy $\sigma p(\widetilde{q})$ given $b=0$. Since the number of users of cash for care increases in $b$ and $t \iiint_{\widetilde{V}_{<}<V^{*}} t w \frac{\partial l^{*}(Y, w, \pi, t, b)}{\partial b} f(Y, w, \pi) d Y d w d \pi<0$, the condition

$$
\begin{aligned}
& -\int_{s}\left\{[t w-\sigma p(\widetilde{q})] \widetilde{l}(Y, w, \pi, t, \sigma)-t w l^{*}(Y, w, \pi, t, b)+b\right\} \\
> & -\iiint_{\widetilde{V}_{<V^{*}}} t w \frac{\partial l^{*}(Y, w, \pi, t, b)}{\partial b} f(Y, w, \pi) d Y d w d \pi
\end{aligned},
$$

has to hold.

(iii) The uniform price subsidy is positive as $\frac{\partial W}{\partial \sigma}>0$ at $\sigma=0$ because $t \iiint_{\widetilde{V}^{\prime} \geq V^{*}} w \frac{\widetilde{\partial l}(Y, w, \pi, t, \sigma)}{\partial \sigma} f(Y, w, \pi) d Y d w d \pi>0$ and $\int_{s}\left\{\left[t w-\sigma p(\widetilde{q}) \widetilde{l}(Y, w, \pi, t, \sigma)-t w l^{*}(Y, w, \pi, t, b)+b\right\}>0\right.$.

With $b>0$ we obtain

$$
\int_{s}\left\{\left[t w-\sigma p(\tilde{q}) \widetilde{]}(Y, w, \pi, t, \sigma)-t w l^{*}(Y, w, \pi, t, b)+b\right\}<0,\right.
$$

according to part (i). Ignoring distributional impacts in Eq. (16), setting $\iiint_{\widetilde{V} \geq V^{*}}\left[\frac{\partial V(Y, w, \pi, t, \sigma)}{\partial \sigma}-\lambda p(\tilde{q}) \widetilde{l}(Y, w, \pi, t, \sigma)\right] f(Y, w, \pi) d Y d w d \pi$ arbitrarily to zero, this in turn implies

$$
\iiint_{\widetilde{V}_{<V^{*}}}[t w-\sigma p(\tilde{q})] \frac{\partial \widetilde{l}(Y, w, \pi, t, \sigma)}{\partial \sigma} f(Y, w, \pi) d Y d w d \pi>0 .
$$

With $b=0$, we obtain

$$
\iiint_{\widetilde{V}<V^{*}}[t w-\sigma p(\tilde{q})] \frac{\widetilde{\partial l(Y, w, \pi, t, \sigma)}}{\partial \sigma} f(Y, w, \pi) d Y d w d \pi+\int_{s}[t w-\sigma p(\tilde{q})] \widetilde{l}>0,
$$

from Eq. (16) since $-t \int_{s} w l^{*}<0$.

(iv) In case of an interior solution, we have

$$
\int_{s}\left\{\left[t w-\sigma p(\tilde{q}) \widetilde{]}(Y, w, \pi, t, \sigma)-t w l^{*}(Y, w, \pi, t, b)+b\right\}<0,\right.
$$

being equivalent to $\int_{s} b<\sigma p(\tilde{q}) \int_{s} \tilde{l}-t \int_{s} w\left(\tilde{l}-l^{*}\right)$. Hence, if $t \int_{s} w\left(\tilde{l}-l^{*}\right)>0$, we obtain $\int_{s} b<\sigma p(\tilde{q}) \int_{s} \tilde{l}$. 


\section{References}

Apps, P., \& Rees, R. (2004). Fertility, taxation and family policy. Scandinavian Journal of Economics, 106 (4), 745-763.

Apps, P., \& Rees, R. (2018). Optimal family taxation and income inequality. International Tax and Public Finance, 25(5), 1093-1128.

Baker, M., Gruber, J., \& Milligan, K. (2008). Universal child care, maternal labor supply and family wellbeing. Journal of Political Economy, 116(4), 709-745.

Bastani, S., Blomquist, S., \& Micheletto, L. (2017). Child care subsidies, quality, and optimal income taxation. CESifo working paper No. 6533, Munich.

Bauernschuster, S., Hener, T., \& Rainer, H. (2016). Children of a (policy) revolution: the introduction of universal child care and its effect on fertility. Journal of the European Economic Association, 14(4), 975-1005.

Bauernschuster, S., \& Schlotter, M. (2015). Public child care and mother's labor supply: evidence from two quasi-experiments. Journal of Public Economics, 123, 1-16.

Bergstrom, T., \& Blomquist, S. (1996). The political economy of subsidized day care. European Journal of Political Economy, 12(3), 443-457.

Bettinger, E., Hægeland, T., \& Rege, M. (2014). Home with mom: the effects of stay-at-home on children`s long-run educational outcomes. Journal of Labor Economics, 32(3), 443-467.

Bick, A. (2016). The quantitative role of child care for female labor participation and fertility. Journal of the European Economic Association, 14(3), 639-668.

Blau, D., \& Currie, J. (2006). Pre-school, day care, and after-school care: who's minding the kids? In E. Hanushek \& F. Welch (Eds.), Handbook of the economics of education, vol 2 (pp. 1163-1278). Amsterdam: Elsevier.

Blau, D., \& Hagy, A. P. (1998). The demand for quality in child care. Journal of Political Economy, 106 (1), 104-146.

Blomquist, S., Christiansen, V., \& Micheletto, L. (2010). Public provision of private goods and nondistortionary marginal tax rates. American Economic Journal: Economic Policy, 2(2), 1-27.

Borck, R., \& Wrohlich, K. (2011). Preferences for child care policies: theory and evidence. European Journal of Political Economy, 27(3), 436-454.

Del Boca, D., \& Vuri, D. (2007). The mismatch between employment and child care in Italy: the impact of rationing. Journal of Population Economics, 20(4), 805-832.

DICE Database. 2011). Use of formal childcare arrangements, 0-2-year-olds, 2005-2009. Munich: Ifo Institute. http://www.cesifo-group.de/DICE/fb/9fTtHHzh.

Domeij, D., \& Klein, P. (2013). Should day care be subsidized? Review of Economic Studies, 80(2), 568-595.

Epple, D., \& Romano, R. (1996a). Ends against the middle: determining public service provision when there are private alternatives. Journal of Public Economics, 62(3), 297-325.

Epple, D., \& Romano, R. (1996b). Public provision of private goods. Journal of Political Economy, 104 (1), 57-84.

Fenge, R., \& Stadler, L. (2014). Three family policies to reconcile fertility and labor supply. CESifo working paper No. 4922, Munich.

Gathmann, C., \& Sass, B. (2018). Taxing childcare: effects on childcare choices, family labor supply, and children. Journal of Labor Economics, 36(3), 665-709.

Guner, N., Kaygusuz, R. \& Ventura, G. (2020) Child-related transfers, household labor supply and welfare. Review of Economic Studies.

Guzman, J. J. (2019). The demand for childcare subsidies under rationing. Review of Economics of the Household, 17(4), 1349-1379.

Havnes, T., \& Mogstad, M. (2011). Money for nothing? Universal child care and maternal employment. Journal of Public Economics, 95(11), 1455-1495.

Havnes, T., \& Mogstad, M. (2015). Is universal child care leveling the playing field? Journal of Public Economics, 127, 100-114.

Heckman, J. J. (1974). Effects on child-care programs on women's work effort. Journal of Political Economy, 82(2), S136-S163.

Herbst, C. M. (2010). The labour supply effects child care costs and wages in the presence of subsidies and the earned income tax credit. Review of Economics of the Household, 8(2), 199-230.

Kemnitz, A., \& Thum, M. (2015). Gender power, fertility, and family policy. Scandinavian Journal of Economics, 117(1), 220-247. 
Kosonen, T. (2014). To work or not to work? The effect of childcare subsidies on the labour supply of parents. B.E. Journal of Economic Analysis and Policy, 14(3), 1-32.

Lefebvre, P., \& Merrigan, P. (2008). Child care policy and the labor supply of mothers with young children: a natural experiment from Canada. Journal of Labor Economics, 26(3), 519-548.

Meier, V., \& Rainer, H. (2015). Pigou meets Ramsey: gender-based taxation with non-cooperative couples. European Economic Review, 77, 28-46.

Morissey, T. W. (2017). Child care and parental labor force participation: a review of the research literature. Review of Economics of the Household, 15(1), 1-24. 